\title{
STATUS ORAL HIGIENE DAN PERIODONTAL PADA PASIEN DIABETES MELITUS DAN NON-DIABETES DI RSUD Dr. PIRNGADI
}

\author{
(ORAL HYGIENE STATUS AND PERIODONTAL DISEASE IN DIABETIC AND NON \\ DIABETIC PATIENTS AT PIRNGADI GENERAL HOSPITAL)
}

\author{
Mardiah Rizqo, Lina Natamiharja \\ Departemen Ilmu Kedokteran Gigi Pencegahan/ Kesehatan Gigi Masyarakat \\ Fakultas Kedokteran Gigi, Universitas Sumatera Utara \\ Jl. Alumni No.2 Kampus USU Medan
}

\begin{abstract}
Diabetes mellitus is a metabolic disorder disease characterized by the increasing of blood glucose occured due to insulin secretion, or both. Diabetes mellitus the systemic diseases that plays a role as a risk of periodontal disease. This study aimed to know oral hygiene status, periodontal and periodentitis old rasio in patients with Diabetes mellitus and non Diabetes. Study design was case control. Study populations were diabetes patients who were treated at Endocrine poli clinic and non diabetes patients at opthamalogic policlinic Pirngadi General Hospital. A total of samples were 100 people, 50 patients were diabetes and the other fifty patients were non diabetes. Samples were take in by using purposive. Sampling teachnique that is purposive sampling, sampling teachnique that is from inclusion criteria until obstained the adjusted amount members. Data collection was done by questainer interview and examination of oral cavity using sample oral hygiene index and periodontal index by Ramfjord. The result of study showed the means of oral hygiene score in diabetes patients type I was $2.06 \pm 1.35$ and in diabetes patients type II was $2.23 \pm 0.97$ where as in non diabetes patients $0.66 \pm 0.33$. The means of periodontal score in diabetes patients type I was $2.72 \pm 0.86$ and diabetes patients type II was $2.69 \pm 0.95$, where as in non diabetes patients $1.07 \pm 0.77$. Oral hygiene of mild diabetes patients found as $64 \%$. The percentage of periodontitis in diabetes patients was $58 \%$ where as an non diabetes patients $28 \%$ and old ratio 6.29 . In conclusion, oral hygiene status in diabetes mellitus patients with the means of oral hygiene score $2.19 \pm 1.05$ including mild category, compared with non diabetes patients was lower $0.66 \pm 0.33$ including good category. Periodontal status in diabetes mellitus patients with the means of periodontal score $2.69 \pm 0.93$ including wild periodontal status compared with non diabetes patients lower $1.07 \pm 0.77$ that is included in good periodontal. Diabetes mellitus patients had 6.29 higher risk suffered from periodontitis compared with non diabetes patients.
\end{abstract}

Key words: oral hygiene, periodontal, diabetes mellitus

\begin{abstract}
Abstrak
Diabetes melitus adalah penyakit gangguan metabolisme ditandai dengan meningkatnya kadar gula darah yang terjadi karena kelainan sekresi insulin, kerja insulin, atau kedua-duanya. Diabetes melitus merupakan salah satu penyakit sistemik yang berperan sebagai faktor risiko penyakit periodontal. Penelitian ini bertujuan untuk mengetahui status oral higiene dan periodontal dan odd rasio periodontitis pada pasien Diabetes melitus dan non-Diabetes. Rancangan penelitian adalah case-control. Populasi penelitian adalah pasien Diabetes melitus yang sedang berobat di Poli Endokrin dan pasien non-Diabetes di Poli Mata RSUD dr. Pirngadi. Jumlah sampel adalah 100 orang, 50 orang menderita Diabetes melitus dan 50 orang yang tidak menderita Diabetes melitus. Pengambilan sampel dilakukan dengan teknik purposive sampling, yaitu sampel diambil sesuai kriteria inklusi sampai diperoleh jumlah sesuai dengan yang ditentukan. Pengumpulan data dilakukan dengan wawancara menggunakan kuesioner dan pemeriksaan klinis rongga mulut menggunakan Indeks Higiene Oral Disederhanakan dan Indeks Periodontal oleh Ramfjord. Hasil penelitian menunjukkan rata-rata skor oral higiene pada pasien Diabetes melitus tipe 1 adalah 2,06 $\pm 1,35$ dan pada pasien Diabetes melitus tipe 2 yaitu 2,23 $\pm 0,97$ sedangkan pada pasien non-Diabetes $0,66 \pm 0,33$. Rata-rata skor periodontal pada pasien Diabetes melitus tipe 1 adalah 2,72 $\pm 0,86$ dan pasien Diabetes melitus tipe 2 yaitu 2,69 $\pm 0,95$, sedangkan pada pasien non-Diabetes 1,07 $\pm 0,77$. Oral higiene pasien Diabetes melitus kategori sedang dijumpai sebanyak 64\% dan non-Diabetes kategori baik $98 \%$. Persentase periodontitis pada pasien Diabetes melitus adalah 58\% sedangkan pada pasien non-Diabetes 18\% dan odd rasio 6,29. Dapat disimpulkan status oral higiene pada pasien Diabetes melitus dengan rata-rata skor oral higiene $2,19 \pm 1,05$
\end{abstract}


termasuk kategori sedang, dibandingkan dengan pasien non-Diabetes lebih rendah yaitu $0,66 \pm 0,33$ dan termasuk kategori baik. Status periodontal pada pasien Diabetes melitus dengan rata-rata skor periodontal 2,69 $\pm 0,93$ termasuk status periodontal sedang dibandingkan dengan pasien non-Diabetes lebih rendah yaitu $1,07 \pm 0,77$ yang termasuk status periodontal baik. Pasien Diabetes melitus mempunyai risiko 6,29 kali lebih besar menderita periodontitis dibandingkan penderita non-Diabetes.

Kata kunci: oral hygiene, periodontal, diabetes mellitus

\section{PENDAHULUAN}

Pada tahun 2003, sekitar 194 juta orang menderita Diabetes melitus di seluruh dunia. Hal tersebut mencapai $5,1 \%$ dari populasi dunia dan jumlah ini diperkirakan akan terus meningkat hingga 333 juta, atau $6,3 \%$ dari populasi dunia pada tahun $2025 .^{3}$ Prevalensi Diabetes melitus di Indonesia sebesar $1,5-2,3 \%$ pada penduduk dengan usia lebih dari 15 tahun, bahkan penelitian di Manado didapatkan prevalensi Diabetes melitus 6,1\%. Pada tahun 2000, penduduk Indonesia yang menderita Diabetes melitus sekitar 5,6 juta orang. ${ }^{4}$ Hasil Riset Kesehatan Dasar (Riskesdas) tahun 2007, prevalensi nasional Diabetes melitus berdasarkan pemeriksaan glukosa darah pada penduduk berusia lebih dari 15 tahun di perkotaan sebesar 5,7\%. Secara epidemiologi, diperkirakan bahwa pada tahun 2030 prevalensi Diabetes melitus di Indonesia mencapai 21,3 juta orang. ${ }^{5}$

Diabetes melitus sebenarnya bukan penyakit yang mematikan, namun yang perlu diwaspadai adalah adanya komplikasi-komplikasi penyakit Diabetes melitus yang menyertai. Keadaan Diabetes melitus dapat merupakan suatu tanda meningkatnya kerentanan terhadap terjadinya infeksi berupa meningkatnya jumlah bakteri sehingga menyebabkan adanya kelainan pada jaringan periodontal. Salah satu komplikasi Diabetes melitus yang cukup serius di bidang kedokteran gigi adalah diabetik oral, yang meliputi mulut kering, gusi mudah berdarah, kalkulus, resorbsi tulang alveolaris, periodontitis dan lain sebagainya., ${ }^{2,6}$ Dari sekian banyak komplikasi yang terjadi, periodontitis merupakan komplikasi yang paling sering terjadi pada penderita Diabetes melitus dengan tingkat prevalensi yang tinggi hingga mencapai angka $75 \%{ }^{6}$

Diabetes melitus merupakan salah satu penyakit sistemik yang dapat berperan sebagai faktor risiko bagi terjadinya periodontitis dan memperburuk kesehatan periodontal. ${ }^{10} \mathrm{Hal}$ ini sesuai dengan penelitian Taylor and Borgnakke menyatakan periodontitis merupakan komplikasi Diabetes melitus. Taylor mengidentifikasikan 48 penelitian pada tahun 1960 sampai tahun 2000, membahas mengenai hubungan penyakit periodontal pada penderita Diabetes melitus dan hasil penelitian dari 44 studi mendukung
Diabetes melitus sebagai faktor risiko terjadinya periodontitis. Bridge dkk. menyatakan Diabetes melitus mempengaruhi semua parameter periodontal, termasuk skor perdarahan, kedalaman saku, kehilangan perlekatan dan kehilangan gigi. ${ }^{11}$ Penelitian Hidayati, Mu'afiro, dan Suwito menyatakan ada pengaruh antara oral higiene terhadap tingkat periodontitis pada penderita Diabetes melitus tipe 2 dengan odd rasio 2,8. Penderita Diabetes melitus dengan kebersihan mulut yang kurang baik dan ada penumpukan kalkulus sering mengalami peradangan gingiva yang parah, pembentukan poket yang dalam dan abses periodontal. ${ }^{6}$

Berdasarkan yang telah diuraikan di atas, peneliti merasa tertarik untuk mengetahui status oral higiene dan periodontal serta odd rasio periodontitis pada pasien Diabetes melitus dan non-Diabetes di RSUD Dr. Pirngadi Medan. Indeks yang digunakan yaitu Oral Hygiene Index Simplified dan Indeks Penyakit Periodontal (Ramfjord). OHIS merupakan indeks untuk menentukan status kebersihan mulut yang terdiri dari pemeriksaan skor debris dan skor kalkulus. Indeks Penyakit Periodontal (Ramfjord) merupakan indeks untuk mengukur keparahan penyakit periodontal dengan menilai komponen penyakit periodontal yaitu gingivitis dan kedalaman saku periodontal. Rumah sakit ini dipilih karena jumlah pasien Diabetes melitus di RSUD Dr. Pirngadi banyak dan mudah ditemui karena pasien melakukan rawat jalan secara berkala.

Tujuan Penelitian adalah Untuk mengetahui ratarata skor oral higiene dan periodontal pada pasien Diabetes melitus dan non-Diabetes. Untuk mengetahui status oral higiene dan periodontal pada pasien Diabetes melitus dan non-Diabetes. Untuk mengetahui odd rasio penyakit periodontal pada pasien Diabetes melitus dan non-Diabetes.

\section{BAHAN DAN METODE}

Penelitian ini merupakan penelitian case control yaitu penelitian non eksperimental yang mempelajari faktor risiko dan efek menggunakan kelompok kasus dan kelompok kontrol. Pada penelitian ini kelompok kasus adalah Diabetes melitus dan kelompok kontrol adalah non-Diabetes.

Penelitian dilakukan di RSUD Dr. Pirngadi 
Medan. Rumah sakit ini dipilih karena jumlah pasien Diabetes melitus dan non-Diabetes di RSUD Dr. Pirngadi banyak dan mudah ditemui karena pasien melakukan rawat jalan secara berkala.

Penelitian ini dilaksanakan mulai bulan Agustus 2012 dan selesai bulan Januari 2014. Penelitian dimulai dari mempersiapkan proposal penelitian, dilanjutkan dengan pelaksanaan penelitian sampai penyusunan laporan akhir.

Populasi penelitian ini adalah pasien yang berobat di RSUD Dr. Pirngadi Medan. Sampel yang diteliti adalah pasien Diabetes melitus di Poli Endokrin SMF Interna RSUD Dr. Pirngadi dan pasien yang tidak menderita Diabetes di Poli Mata RSUD Dr. Pirngadi yang sesuai dengan kriteria inklusi dan bersedia dilakukan penelitian.

Berdasarkan perhitungan diperoleh besar sampel 50 orang. Pada penelitian ini diambil kelompok yang menderita Diabetes melitus berjumlah 50 orang dan kelompok yang non-Diabetes berjumlah 50 orang. Sehingga didapat jumlah seluruh sampel pada penelitian ini berjumlah 100 orang.

Sampel diambil dengan menggunakan cara purposive sampling, di mana pemilihan subjek penelitian bertitik tolak pada ciri-ciri karakteristik populasi yang ditetapkan dalam kriteria inklusi sampai diperoleh jumlah sampel sesuai dengan yang sudah ditentukan.

Kriteria Inklusi meliputi usia 30-50 tahun, bersedia menjadi sampel penelitian dengan menandatangani lembar persetujuan setelah penjelasan, sedangkan kriteria eksklusi meliputi pasien yang merokok, pasien yang mendapatkan perawatan pembersihan karang gigi dalam 6 bulan terakhir.

Pasien yang menderita penyakit sistemik lain (penyakit darah seperti leukemia dan anemia, penyakit vaskular seperti jantung koroner dan arterosklerosis, dan penyakit saluran pernafasan seperti chronic pulmonary disease dan pneumonia).

Pengumpulan data karakteristik responden dilakukan dengan melakukan wawancara menggunakan kuesioner. Responden yang menderita Diabetes melitus diperoleh melalui rekam medik pasien yang berkunjung ke Poli Endokrin SMF Interna RSUD Dr. Pirngadi dan responden non-Diabetes yang berkunjung ke Poli Mata RSUD Dr. Pirngadi. Responden diberikan lembar penjelasan penelitian. Bila responden bersedia berpartisipasi dalam penelitian, maka responden menandatangani lembar informed consent.

Pengumpulan data status oral higiene diperoleh dengan memeriksa rongga mulut menggunakan kaca mulut dan sonde yang berbentuk sabit tanpa menggunakan zat pewarna. Pengukuran dilakukan pada gigi $16,11,26,36,31$, dan 46 . Pada gigi 16 ,
11, 26, 31 yang dilihat permukaan bukalnya sedangkan gigi 36 dan 46 permukaan lingualnya. Pemeriksaan oral higiene terdiri atas dua komponen, yaitu Indeks debris dan Indeks kalkulus. Untuk mengukur indeks debris, sonde ditempatkan pada insisal gigi kemudian digerakkan ke arah mesial dan distal, selanjutnya bergerak ke arah gingiva setiap 1/3 permukaan gigi dan skor diberikan sesuai kriteria. Pengukuran indeks kalkulus dilakukan dengan menempatkan ujung sonde pada daerah subgingiva terlebih dahulu, kemudian digerakkan dari mesial ke distal dan naik ke arah insisal dan diberi skor sesuai kriteria.

Pengumpulan data status periodontal diperoleh dengan memeriksa rongga mulut menggunakan indeks periodontal Ramfjord. Pengukuran dilakukan hanya pada enam gigi indeks yaitu gigi 16, 21, 24, 36, 41, dan 44. Bila salah satu gigi ini hilang maka akan digantikan oleh gigi disampingnya $(17,11,25,37,42$, dan 45). Pengukuran dilakukan menggunakan kaca mulut dan prob periodontal WHO yang mempunyai kalibrasi dalam milimeter dan mempunyai batas warna hitam 3-6 mm. Pengukuran dilakukan pada sisi vestibular di bagian tengahnya, sudut mesiovestibular pada daerah kontak interproksimal, bagian tengah permukaan oral dan sudut disto oral daerah kontak interproksimal. Pada waktu pengukuran pada sudut mesio vestibular dan disto oral, prob dalam keadaan berkontak dengan gigi.

Hasil pemeriksaan oral higiene dan periodontal dicatat pada formulir yang tersedia. Pengumpulan data dilakukan oleh peneliti dan dibantu 3 orang tenaga peneliti lainnya. Untuk menghindari terjadinya kesalahan pengukuran maka kepada pengumpul data dilakukan kalibrasi sehingga diperoleh interpretasi yang sama.

Pengolahan data dilakukan menggunakan sistem komputerisasi. Analisis data dilakukan dengan menghitung odd rasio periodontitis antara penderita Diabetes melitus dan non-Diabetes.

\section{HASIL}

Persentase responden Diabetes melitus yang berusia 41-50 tahun lebih banyak yaitu $88 \%$ dan berusia 30-40 tahun $12 \%$. Persentase responden Diabetes melitus berjenis kelamin perempuan lebih banyak yaitu $76 \%$ dan laki-laki $24 \%$.

Persentase responden non-Diabetes berusia 41-50 tahun juga lebih banyak yaitu $60 \%$ dan yang berusia 30-40 tahun 40\%. Persentase responden berjenis kelamin perempuan juga lebih banyak yaitu $66 \%$ dan laki-laki 34\% (Tabel 1).

Rata-rata skor debris pada pasien Diabetes melitus tipe 1 adalah $0,8 \pm 0,52$ sedangkan pada pasien Dia- 
betes melitus tipe 2 lebih tinggi yaitu $0,9 \pm 0,58$. Total rata-rata skor debris pada pasien Diabetes melitus adalah $0,88 \pm 0,56$ sedangkan pada pasien non-Diabetes lebih rendah yaitu $0,47 \pm 0,28$.

Rata-rata skor kalkulus pada pasien Diabetes melitus tipe 1adalah $1,26 \pm 1,35$ sedangkan pada pasien Diabetes melitus tipe 2 lebih tinggi yaitu 1,33 \pm 0,53 . Total rata-rata skor kalkulus pada pasien Diabetes melitus adalah $1,31 \pm 0,61$ sedangkan pada pasien non-Diabetes lebih rendah yaitu $0,19 \pm 0,23$ (Tabel 2).

Tabel 1. Persentase karakteristik responden pasien Diabetes melitus dan non-Diabetes di RSUD dr. Pirngadi $(n=100)$

\begin{tabular}{lcccc}
\hline Karakteristik & \multicolumn{2}{c}{ Diabetes melitus } & \multicolumn{2}{c}{ Non-Diabetes } \\
\cline { 2 - 5 } responden & $\mathrm{n}$ & $\%$ & $\mathrm{n}$ & $\%$ \\
\hline Usia (tahun) & & & & \\
$30-40$ & 6 & 12 & 20 & 40 \\
$41-50$ & 44 & 88 & 30 & 60 \\
\hline Jenis Kelamin & & & & \\
Laki-Laki & 12 & 24 & 17 & 34 \\
Perempuan & 38 & 76 & 33 & 66 \\
\hline
\end{tabular}

Tabel 2. Rata-rata skor indeks debris dan kalkulus pada pasien Diabetes melitus dan non-Diabetes di RSUD dr. Pirngadi

\begin{tabular}{lcc}
\hline \multirow{1}{*}{\multicolumn{1}{c}{ Pasien }} & $\begin{array}{c}\text { Indeks } \\
\text { debris }\end{array}$ & $\begin{array}{c}\text { Indeks } \\
\text { kalkulus }\end{array}$ \\
\cline { 2 - 3 } & $\bar{x} \pm \mathrm{SD}$ & $\bar{x} \pm \mathrm{SD}$ \\
\hline Diabetes Melitus Tipe 1 & $0,8 \pm 0,52$ & $1,26 \pm 1,35$ \\
Diabetes Melitus Tipe 2 & $0,9 \pm 0,58$ & $1,33 \pm 0,53$ \\
Diabetes Melitus & $0,88 \pm 0,56$ & $1,31 \pm 0,61$ \\
Non-Diabetes & $0,47 \pm 0,28$ & $0,19 \pm 0,23$ \\
\hline
\end{tabular}

Rata-rata skor oral higiene pada pasien Diabetes melitus tipe 1 adalah 2,06 $\pm 1,35$ sedangkan pada pasien Diabetes melitus tipe 2 lebih tinggi yaitu 2,23 $\pm 0,97$. Total rata-rata skor oral higiene pada pasien Diabetes melitus adalah 2,19 $\pm 1,05$ dibandingkan dengan pasien non-Diabetes lebih rendah yaitu $0,66 \pm 0,33$.

Rata-rata skor periodontal pada pasien Diabetes melitus tipe 1 adalah 2,72 $\pm 0,86$ sedangkan pada pasien Diabetes melitus tipe 2 lebih rendah yaitu $2,69 \pm 0,95$. Total rata-rata skor periodontal pada pasien Diabetes melitus adalah 2,69 $\pm 0,93$ dibandingkan dengan pasien non-Diabetes lebih rendah yaitu $1,07 \pm 0,77$ (Tabel 3).

Persentase status oral higiene pada pasien Diabetes melitus tipe 1 adalah kategori baik 36,4\%, kategori sedang $36,4 \%$ dan kategori buruk $27,3 \%$. Pada pasien Diabetes melitus tipe 2 kategori sedang 71,8\%, kategori buruk 17,9\% dan kategori baik 10,3\%.
Total persentase status oral higiene pada pasien Diabetes melitus sebanyak 64\% termasuk kategori sedang, kategori buruk 20\% dan kategori baik 16\%, sedangkan pasien non-Diabetes kategori baik $98 \%$, kategori sedang 2\% dan kategori buruk tidak ada (Tabel 4).

Tabel 3. Rata-rata skor oral higiene dan periodontal pasien Diabetes melitus dan non-Diabetes

\begin{tabular}{lcc}
\hline \multirow{1}{*}{ Pasien } & OHIS & $\begin{array}{c}\text { Indeks } \\
\text { Periodontal }\end{array}$ \\
\cline { 2 - 3 } & $\bar{x} \pm$ SD & $\bar{x} \pm$ SD \\
\hline Diabetes Melitus Tipe 1 & $2,06 \pm 1,35$ & $2,72 \pm 0,86$ \\
Diabetes Melitus Tipe 2 & $2,23 \pm 0,97$ & $2,69 \pm 0,95$ \\
Diabetes Melitus & $2,19 \pm 1,05$ & $2,69 \pm 0,93$ \\
Non-Diabetes & $0,66 \pm 0,33$ & $1,07 \pm 0,77$ \\
\hline
\end{tabular}

Tabel 4. Persentase status oral higiene pada pasien Diabetes melitus dan non-Diabetes di RSUD dr. Pirngadi

\begin{tabular}{|c|c|c|c|c|c|c|}
\hline \multirow{3}{*}{ Pasien } & \multicolumn{6}{|c|}{ Oral higiene } \\
\hline & \multicolumn{2}{|c|}{ Baik } & \multicolumn{2}{|c|}{ Sedang } & \multicolumn{2}{|c|}{ Buruk } \\
\hline & $\mathrm{n}$ & $\%$ & $\mathrm{n}$ & $\%$ & $\mathrm{n}$ & $\%$ \\
\hline Diabetes melitus Tipe 1 & 4 & 36,4 & 4 & 36,4 & 3 & 27,3 \\
\hline Diabetes melitus Tipe 2 & 4 & 10,3 & 28 & 71,8 & 7 & 17,9 \\
\hline Diabetes & 8 & 16 & 32 & 64 & 10 & 20 \\
\hline Non-Diabetes & 49 & 98 & 1 & 2 & 0 & 0 \\
\hline
\end{tabular}

Persentase periodontitis pada pasien Diabetes melitus lebih adalah 58\% dibandingkan pada pasien non-Diabetes $18 \%$ dan persentase yang tidak menderita periodontitis pada pasien Diabetes melitus adalah $42 \%$ dan pada pasien non-Diabetes $82 \%$ dengan odd rasio sebesar 6,29, yang berarti risiko periodontitis pada pasien Diabetes melitus 6,29 kali lebih besar dibandingkan pasien non-Diabetes (Tabel 5).

Tabel 5. Odd rasio periodontitis pada pasien Diabetes melitus dan non-Diabetes di RSUD dr. Pirngadi

\begin{tabular}{|c|c|c|c|c|c|}
\hline \multirow{3}{*}{ Pasien } & \multicolumn{4}{|c|}{ Periodontitis } & \multirow{3}{*}{ Odd rasio } \\
\hline & \multicolumn{2}{|c|}{$\mathrm{Ya}$} & \multicolumn{2}{|c|}{ Tidak } & \\
\hline & $\mathrm{n}$ & $\%$ & $\mathrm{n}$ & $\%$ & \\
\hline Diabetes melitus & 29 & 58 & 21 & 42 & 6,29 \\
\hline Non-Diabetes & 9 & 18 & 41 & 82 & \\
\hline
\end{tabular}

\section{PEMBAHASAN}

Hasil penelitian menunjukkan rata-rata skor debris pada pasien Diabetes melitus tipe 1 adalah $0,8 \pm$ 0,52 sedangkan pada pasien Diabetes melitus tipe 2 lebih tinggi yaitu $0,9 \pm 0,58$. Total rata-rata skor debris pada pasien Diabetes melitus adalah 0,88 \pm 0,56 yang termasuk kategori sedang, dibandingkan 
pada pasien non-Diabetes lebih rendah yaitu $0,47 \pm$ 0,28 dan termasuk kategori baik. Rata-rata skor kalkulus pada pasien Diabetes melitus tipe 1 adalah $1,26 \pm 1,35$ sedangkan pada pasien Diabetes melitus tipe 2 lebih tinggi yaitu $1,33 \pm 0,53$. Total rata-rata skor kalkulus pada pasien Diabetes melitus adalah $1,31 \pm 0,61$ sedangkan pada pasien non-Diabetes lebih rendah yaitu $0,19 \pm 0,23$.

Rata-rata skor oral higiene pada pasien Diabetes melitus tipe 1 adalah 2,06 $\pm 1,35$ sedangkan pada pasien Diabetes melitus tipe 2 lebih tinggi yaitu 2,23 \pm 0 ,97. Status oral higiene pada pasien Diabetes melitus dengan rata-rata skor oral higiene 2,19 \pm 1,05 termasuk kategori sedang, dibandingkan dengan pasien non-Diabetes lebih rendah yaitu $0,66 \pm$ 0,33 dan termasuk kategori baik. Persentase status oral higiene terbanyak pada pasien Diabetes melitus tipe 1 adalah kategori baik $36,4 \%$ dan kategori sedang $36,4 \%$ sedangkan pada pasien Diabetes melitus tipe 2 adalah kategori sedang $71,8 \%$. Total persentase status oral higiene pasien Diabetes melitus terbanyak adalah kategori sedang $64 \%$, sedangkan pada pasien non-Diabetes sebanyak $98 \%$ termasuk dalam kategori baik. Hal ini menunjukkan pasien Diabetes melitus baik Diabetes melitus tipe 1 maupun tipe 2 kurang menjaga kebersihan gigi dan mulut sehingga plak/ sisa makanan yang menempel di permukaan gigi lama-kelamaan mengeras dan membentuk kalkulus dan akan memperburuk kesehatan jaringan periodontalnya. ${ }^{6}$

Kondisi oral higiene yang lebih buruk pada pasien Diabetes melitus menyebabkan persentase periodontitis pada pasien Diabetes melitus lebih tinggi yaitu $58 \%$, sedangkan pada pasien non-Diabetes persentase periodontitis $18 \%$. Angka odd rasio pada pasien Diabetes melitus dan non-Diabetes adalah 6,29. Hal ini menunjukkan pasien Diabetes melitus mempunyai risiko 6,29 kali lebih besar menderita periodontitis dibandingkan pasien non-Diabetes. Hasil ini sesuai dengan yang dikemukakan oleh Nandya dkk. yang menyatakan pasien Diabetes melitus memiliki tingkat kerusakan jaringan periodontal yang lebih parah dibandingkan dengan yang tidak menderita Diabetes karena Diabetes dapat meningkatkan risiko kerusakan jaringan periodontal yang berlanjut dari waktu ke waktu. ${ }^{23}$

Rata-rata skor periodontal pasien Diabetes melitus tipe 1 adalah $2,72 \pm 0,86$ sedangkan pada pasien Diabetes melitus tipe 2 lebih rendah yaitu 2,69 $\pm 0,95$. Total rata-rata skor periodontal pada pasien Diabetes melitus adalah 2,69 $\pm 0,93$ dan termasuk status periodontal sedang dibandingkan dengan pasien non-Diabetes lebih rendah yaitu $1,07 \pm 0,77$ dan termasuk status periodontal yang baik. Hal ini dapat disebabkan karena kadar glukosa darah yang tinggi dan kebersihan gigi dan mulut yang kurang terjaga meningkatkan kerusakan periodontal pada pasien Diabetes melitus. Hasil ini sesuai dengan penelitian Hidayati dkk. menyatakan pasien Diabetes melitus dengan skor OHIS tinggi semakin berisiko menderita periodontitis 2,8 kali dibandingkan dengan OHIS rendah. ${ }^{6}$ Diabetes melitus dapat meningkatkan prevalensi dan memperparah kondisi jaringan periodontal. ${ }^{22}$ Pada pasien Diabetes melitus, meningkatnya kadar glukosa dalam darah dan cairan gingiva berarti juga merubah lingkungan mikroflora, menginduksi perubahan bakteri secara kualitatif sehingga perubahan tersebut meningkatkan kerusakan jaringan periodontal dan dapat mengarah pada penyakit periodontal yang berat. ${ }^{8,23,27}$

Berdasarkan hasil penelitian dapat disimpulkan bahwa status oral higiene pada pasien Diabetes melitus dengan rata-rata skor oral higiene 2,19 \pm 1,05 termasuk kategori sedang, dibandingkan dengan pasien non-Diabetes lebih rendah yaitu $0,66 \pm$ 0,33 dan termasuk kategori baik. Persentase status oral higiene pasien Diabetes melitus terbanyak adalah 64\% termasuk kategori sedang, sedangkan pada pasien non-Diabetes sebanyak $98 \%$ termasuk dalam kategori baik. Rata-rata skor periodontal pasien Diabetes melitus tipe 1 adalah 2,72 $\pm 0,86$ sedangkan pada pasien Diabetes melitus tipe 2 lebih rendah yaitu $2,69 \pm 0,95$. Rata-rata skor periodontal pada pasien Diabetes melitus adalah 2,69 $\pm 0,93$ dan termasuk status periodontal sedang dibandingkan dengan pasien non-Diabetes lebih rendah yaitu $1,07 \pm$ 0,77 dan termasuk status periodontal yang baik. Pada pasien Diabetes melitus, persentase yang menderita periodontitis $58 \%$ sedangkan pada pasien non-Diabetes lebih rendah yaitu $18 \%$, yang berarti pasien Diabetes melitus mempunyai risiko 6,29 kali lebih besar menderita periodontitis dibandingkan pasien non-Diabetes.

\section{Daftar Pustaka}

1. Sudoyo AW, Setiyohadi B, Alwi I, Simadibrata M, Setiati S. Buku Ajar Ilmu Penyakit Dalam. Edisi 5. Jakarta: Interna, 2009: 1873-85.

2. Harijanti K, Soebadi B, Mulyaningsih I. Prevalence of xerostomia on type 2 Diabetes melitus in Hajj Hospital Surabaya. Majalah Kedokteran Gigi 2007; 40: 136-9.

3. Kementerian Kesehatan Republik Indonesia. Tahun 2030 prevalensi Diabetes melitus di Indonesia mencapai 21,3 juta orang. $<$ http://www. depkes. go.id/index. pjp/berita/pressrelease/414tahun-2030prevalensi-Diabetes-melitus-di-indonesia-mencapai213-juta-orang.pdf $>$ (1 Agustus 2012).

4. Hidayati S, Mu'afiro A, Suwito J. Analisis faktor yang berhubungan dengan tingkat keparahan periodontitis pada pasien DM tipe 2 di Poli Diabetes 
RSU Dr. Soetomo Surabaya. Buletin Penelitian RSU Dr Soetomo 2008; 10: 49-54.

5. Oktanauli P, Fani IR, Aldiba A. Aspek imunologi rongga mulut pada pasien Diabetes melitus. JITEKGI 2011; 8: 46-50.

6. Dalimunthe SH. Periodonsia. Edisi ke-2. Medan: Bagian Periodonsia Fakultas Kedokteran Gigi Universitas Sumatera Utara, 2008: 66-72, 99-101, 10610, 114-5, 136-40.

7. Pintauli S, Hamada T. Menuju gigi dan mulur sehat: pencegahan dan pemeliharaan. Medan: USU Press, 2012: 29-32, 40, 68-71.

8. Daniel SJ, Harfst SA, Wilder RS, Francis B, Mitchell SH. Mosby's dental hygiene: concepts, case and competencies. $2^{\text {nd }}$ ed. Missouri: Mosby Elsevier, 2008: 866-9.

9. Suyono S, Waspadji S, Soegondo S, Soewondo P, Subekti I, Semiardji G, dkk. Penatalaksanaan Diabetes melitus terpadu. Edisi 2. Jakarta: Fakultas Kedokteran Universitas Indonesia, 2009: 11-28, 70-1.

10. Little JW, Falace DA, Miller CS, Rhodus NL. Dental management of the medically compromised patient. $7^{\text {th }}$ ed. Missouri: Mosby Elsevier, 2008: 214-6.

11. Lamster IB, Lalla E, Borgnakke WS, Taylor GW. The relationship between oral health and Diabetes melitus. J Am Dent Assoc 2008; 139: 19S-24S.

12. Mealey BL. Periodontal disease and Diabetes: A two-way street. J Am Dent Assoc 2006; 137: 26S-31S
13. Graves DT, Liu R, Oates TW. Diabetes-enhanced inflammation and apoptosis-impact on periodontal pathosis. Periodontology 2000 2007; 45: 128-37.

14. Wijayanti PM, Setyopranoto I. Hubungan antara periodontitis, aterosklerosis dan stroke iskemik akut. Mutiara Medika 2008; 8: 120-8.

15. Nascimento TC, Costa M, Suzart I, Vianna MI, Santos CT. Factor related to periodontal disease in a rural population. Braz Oral Res 2006; 20: 257-62.

16. Pejcic A, Obradovic R, Kesic L, Kojovic D. Smoking and periodontal disease: A review. Medicine and Biology 2007; 14: 53-9.

17. Matu NK, Stephen L, Lalloo R. Prevalence and severity of periodontal disease: type 2 Diabetics versus non-diabetics. SADJ 2009; 64: 64-8.

18. Nandya, Maduratna E, Augustina EF. Status kesehatan jaringan periodontal pada pasien Diabetes melitus tipe 2 dibandingkan dengan pasien non Diabetes melitus berdasarkan GPI. <http:// journal. unair.ac.id/filerPDF/ejournal\%Status $\% 20$ kesehatan \%20jaringan \%20periodontal.pdf $>$ (29 Juli 2012).

19. Manson JD, Eley BM. Periodontics. $5^{\text {th }}$ ed. Philadelphia: Wright, 2004: 124.

20. Perry DA, Beemsterboer P. Periodontology for the dental hygienist. $3^{\text {rd }}$ ed. Missouri: Saunders Elsevier, 2007: 49.

21. Pathak AK, Shakya VK, Chandra A, Goel K. Association between Diabetes melitus and periodontal status in North Indian adults. European Journal of General Dentistry 2013; 2: 58-61. 